Anuario Latinoamericano

Ciencias Políticas

y Relaciones Internacionales

vol. 10, 2020

pp. 221-224

DOI:10.17951/al.2020.10.221-224

\section{Sergio Pacheco González. Strategies and Rearrangements of Masculinities in a Border Environment, Editora CRV, Curitiba 2019, pp. 174. ISBN: 978-85-444-3895-4, DOI: $10.24824 / 978854443895.4$}

Sergio Pacheco González. Estrategias entorno fronterizo, Editora CRV, DOI: $10.24824 / 978854443895.4$ 
utilizadas al sentir la afectación de lo suyo desde diferentes narrativas generacionales.

De esta forma, se examina la construcción de las masculinidades a partir de tres historias de vida y los tránsitos de los ambientes rural a urbano, y la técnica de grupos focales, con la finalidad de ubicar la distancia entre el significante flotante, y el significante vacío del concepto masculinidad. El texto destaca nociones de contenido ideológico que encubren múltiples relaciones, y una velada crítica a la oposición binaria masculino / femenino, como resultado insuficiente para comprender la complejidad en la variación de sentidos, y su articulación en la cadena de combinaciones que muestran el vacío del concepto de la masculinidad, para sustituirlo por una construcción integradora representada por el concepto de las masculinidades. De esta manera el autor anota:

En otras palabras, si masculinidad significa respeto, protección, respaldo, proveeduría, autoridad, guía, ejemplo, fortaleza y más -y todo al mismo tiempo-, lo que se tiene es un exceso de sentido que, para hacerlo comprensible, requiere especificar qué de los eslabones que forman la cadena de equivalencias es pertinente y qué se distingue del significante mismo, de tal suerte que se identifique, si es que existe, su posible sentido originario. (p. 151)

El aporte de este texto consiste en presentar, desde el análisis de los casos, una crítica al concepto de la masculinidad y masculinidad hegemónica, con distancia en los mandatos de los atributos, los cuales se han robustecido a partir de mostrar el conjunto de creencias prácticas que definen al hombre como masculino. La autoidentificación de los hombres con diferentes rangos de edad y la evaluación de sus relaciones forman parte del análisis como producto del trabajo de campo.

¿Qué define a un hombre? Si masculinidad no es igual a responsabilidad, protección y siempre la capacidad de resolver, ¿dónde está el significante?, ¿cuáles han sido las significaciones predominantes que han limitado el análisis para ubicar el abanico de diferencias? Lo mismo sucede con el conjunto de cargas atribuidas, tal como la obligación como trabajador y proveedor. Lo que descubre la competencia que libran los hombres entre sí, ahora con las mujeres quienes se incorporan y asisten con regularidad al mercado laboral.

La crisis que coloca el monopolio para trabajar y proveer se trasladada ahora a una carga compartida. De esta forma, se modifica el sistema sexogénero y el ámbito de su existencia en la sociedad, distanciando la limitante de la exclusividad de los espacios fuera de casa como sólo de y para hombres, y desdibujando el contenido del concepto construido a partir de la masculinidad hegemónica en las condiciones del territorio de Ciudad Juárez.

Mientras la noción de hombre como concepto genérico y universal se desvanece, posibilitando el reconocimiento de la heterogeneidad social, reforzado con los discursos feministas, también esta articulación se presenta por par- 
te de los discursos feministas, lo que aviva la significación de la masculinidad como cadena de equivalencia en Ciudad Juárez.

Un elemento para destacar es la renegociación de posiciones en el arreglo familiar, en las relaciones interpersonales y en los espacios públicos que formaron parte de la crisis social extendida a la identidad de género, la cual se expresó en múltiples episodios de violencia, incluidos los feminicidios en el territorio. Estas tensiones muestran la expresión más clara y violenta de la dominación de género.

El texto visibiliza la violencia que encubre condiciones de vulnerabilidad descubierta, a la cual se suma la incapacidad. Ambos condicionantes forman parte del ejercicio de las expresiones de masculinidad. Trabajador, proveedor, jefe de familia son atributos no exclusivos de los hombres.

La propuesta del libro es provocadora ante los discursos hegemónicos, al ubicar construcciones alternativas que invitan a reflexionar sobre posiciones de igualdad y equidad de género. Además, visibiliza la necesidad de reconocer el ejercicio diferenciado de la masculinidad, desde el cambio hacia una comprensión de las masculinidades.

La sustitución del portador en la jefatura de familia es un ejemplo de este cambio, que no necesariamente significa la ausencia de un hombre en el hogar. No obstante, esta transformación muestra un discurso inclinado a la víctima por parte de los integrantes del grupo focal más joven.

La presentación de la obra destaca el reconocimiento de la dominación y la disputa por el poder en este lugar fronterizo con dinámico crecimiento económico. La introducción no sólo narra cada capítulo, también destaca la articulación de cambios en distintos sentidos.

Sin duda, los cuadros 1 y 2 del primer capítulo ayudan al autor a desarrollar la perspectiva de género, a partir de la mirada al sistema sexo-género y su caracterología de diferenciación entre aquello considerado femenino y su distancia con la construcción de la virilidad, desde el conjunto de mitos construidos, culturalmente validados y por tanto socializados, que dan como resultado, por ejemplo, la combinación de sumisión en contraste con la dominación y el autoritarismo. Este mismo capítulo conduce al apartado que analiza las relaciones de género como relaciones de poder, y también el carácter político del estudio de las masculinidades. De esta forma, a partir de la revisión de distintas construcciones teóricas se llega a reflexiones sobre la conexión que se presenta entre la dominación y la violencia.

El segundo capítulo se centra en contextualizar las crisis en Ciudad Juárez, pero también ubica formaciones discursivas de creencias sobre el comportamiento y las actitudes de los habitantes fronterizos, así como el conjunto de atributos masculinizados en el uso de la fuerza.

El tercer capítulo explica las decisiones asumidas para construir la investigación desde posiciones epistemológicas y de metodología de estudio, definiendo la estrategia del análisis del discurso como la mejor ruta para desarrollar los objetivos del trabajo.
Anuario Latinoamericano Ciencias Políticas y Relaciones Internacionales vol. 10, 2020

pp. 221-224

DOI:10.17951/al.2020.10.223-224 
El significado de ser hombre se desarrolla en el cuarto capítulo, a través de ubicar cadenas discursivas y el resultado de las narrativas de entrevistados e integrantes de los grupos focales. Las condiciones de vida y la distancia generacional muestran perspectivas distintas asociadas con conductas y gustos. Incluso el trato hacia una mujer cambia según su valoración, tal como lo relata el Señor Isaac nacido en un ejido de Coahuila, quien afirma que hay mujeres a quien se les puede faltar el respeto, trato contrario al que se da a la esposa y madre de los hijos.

Las narrativas presentadas en este último capítulo combinan actitudes, emociones y pensamientos de los hombres quienes participaron en este estudio, a partir de sus discursos, tal como, por ejemplo, ubicar el manejo de una troca (camioneta) como exclusivo de hombres que además aporta una posición de superioridad. Incluso, se identifica claramente la diferencia en la aplicación de la ley -que ocurre entre el lado mexicano y el lado estadounidense-, y su impacto en los comportamientos.

El campo semántico de los contenidos generacionales para el ejercicio de Ser Hombre se presenta en este capítulo e ilustra el cambio entre el adulto mayor para cumplir sexualmente a una mujer, y la narrativa juvenil que sostiene en ese mismo tema la necesidad del respaldo de la mujer, tal como se presenta en la tabla que resume el análisis de los datos.

El trabajo en su conjunto destaca los contrastes tanto discursivos como de expresiones, que ayudan en la construcción del cuadro semántico comparado.

Yo nací como hombre, crecí como hombre y con la creencia que la cultura ha dado, que uno es la cabeza del hogar y que la mujer es, la mujer es, quien debe aceptar las órdenes. Entonces mi esposa de allá trae también la creencia de que el hombre manda y que ella acepta, eh. (Sergio, 68 años, originario de Matamoros, Tamaulipas, p. 136)

Los mapas conceptuales 1 y 2 presentan en las conclusiones el contenido de la masculinidad como significante flotante y vacío. En este último apartado de reflexiones sobre el trayecto de la investigación y análisis de los datos, el autor destaca que, ante la articulación de cadenas de equivalencias, tales como hombre-violento y mujer-trabajadora, se perfila el reconocimiento a la existencia de la cadena de equivalencia de hombre-considerado-respetuoso y colaborador, aunque advierte la aún débil trascendencia en la ideología sobre prácticas constantes en el ejercicio del género.

La obra es una lectura obligada para quienes abordan estudios de género en y desde el siglo XXI.

Rosa Ynés Alacio-García Universidad Autónoma de la Ciudad de México 